\title{
Review of Leishmaniasis in the Middle East and North Africa
}

\author{
Ahmed Tabbabi
}

Department of Hygiene and Environmental Protection, Ministry of Public Health, Tunis, Tunisia

\begin{abstract}
Background: Cutaneous and visceral forms of leishmaniasis are the most important protozoan infection in the Middle East and North Africa (MENA).

Objectives: Review the current knowledge on leishmaniasis in the MENA.

Methods: The data presented in this review are gathered primarily from WHO reports and from an extensive literature search on PubMed.

Results: There are four cycles of transmission of leishmaniasis: zoonotic cutaneous leishmaniasis (ZCL), induce by Leishmania (L.) major, transmitted by Phlebotomus (P.) papatasi, with rodent species of Psammomys obesus, Meriones libycus, Nesokia indica, and Rhombomys opimus are considered as host reservoirs. Zoonotic visceral leishmaniasis (ZVL) is inducing by L. infantum, transmitted by several Phlebotomus spp. of the sub-genus Larroussius and mainly P. perniciosus in more than one-half of the MENA countries and the dog species of Canis familiaris are considered as the main reservoirs. Anthroponotic cutaneous leishmaniasis (ACL), induce by L. tropica and transmitted by P. sergenti, without any non-human reservoir in most cases. Anthroponotic visceral leishmaniasis (AVL) induces by L. donovani spreads through $P$. alexandri, circulates exclusively in humans.

Conclusion: There are many challenges facing the successful control of leishmaniasis. However, there is continuing research into the treatment of leishmaniasis and potentially vaccinations for the disease.

Keywords: Cutaneous and visceral leishmaniasis, global distribution, Middle East and North Africa.

DOI: https://dx.doi.org/10.4314/ahs.v19i1.4

Cite as: Tabbabi A. Review of Leishmaniasis in the Middle East and North Africa. Afri Health Sci. 2019;19(1): 1329-1337. https://dx.doi. org/10.4314/ahs.v19i1.4
\end{abstract}

\section{Introduction}

Leishmaniasis is an important complex of protozoal vector-borne diseases that affects both humans and animals. It is caused by parasites of the Leishmania type and spread by the bite of certain types of sandflies. These organisms are mainly maintained and circulate in animals. Indeed, each Leishmania species having specific mammal reservoir hosts and vectors ${ }^{1}$. It should be noted that the prevention of leishmaniasis is difficult due to the significant side effects that cause drugsused for treatment and their limited availability outside endemic regions.

\section{Corresponding author:}

Ahmed Tabbabi,

Department of Hygiene and Environmental

Protection, Ministry of Public Health,

Tunis, Tunisia.

Email: tabbabiahmed@gmail.com
There are several different forms of leishmaniasis in people. It comes mainly in two forms: cutaneous and visceral leishmaniasis, which causes skin sores and affects several internal organs, respectively. It is important to note that a single species can cause both visceral and cutaneous leishmaniasis and can produce lesions with different characteristics in the same person ${ }^{2-5}$. However, generally different species of the Leishmania parasite are associated with each form. Further investigations are needed to determine factors that cause different disease manifestations of the same species, but it seems that specific factors are probably influenced by genetic hybrids occurring between Leishmania species ${ }^{6,7}$, the host immune response ${ }^{8}$, and less likely by different sand fly vector species ${ }^{9-11}$ since the existence of a vector-parasite specificity although this specificity may be flexible and not completely strict.

Fatality rates for leishmaniasis are the third highest of all the neglected tropical diseases after sleeping sickness and

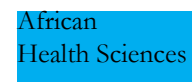

(C) 2019 Tabbabi. Licensee African Health Sciences. This is an Open Access article distributed under the terms of the Creative commons Attribution License (https://creativecommons.org/licenses/BY/4.0), which permits unrestricted use, distribution, and reproduction in any medium, provided the original work is properly cited. 
chagas disease. However, the morbidity due to the disease is often confused and underestimated by clinicians and scientists. This underestimation of the true health burden of leishmaniasis is due to several reasons. First, the mandatory reporting of leishmaniasis cover only 32 of the 88 affected countries. Second, it is known that the disease is embedded in poverty and is typically kept hidden by the affected individuals and their families due to its low mortality rates. Finally, other factors including mainly economic troubles and civil war have participated hugely in the spread and the underestimate of leishmaniasis. Globally, the World Health Organization (WHO) has estimated that 2 million new cases occur yearly $(75 \%$ for cutaneous leishmaniasis and 25\% for visceral leishmaniasis) and that 12 million people are infected globally ${ }^{12}$. About 100,000 cases of leishmaniasis were reported in the MENA region and neighboring countries in 2008. With respect to visceral leishmaniasis, Sudan and Somalia reported 4108 and 583 cases of AVL, respectively. As regards ZVL, 409 cases were reported from five countries: Iran 125; Morocco 163; Saudi Arabia 41; Syria 17 and Tunisia 63 . This number should be higher than the recorded one if we take into consideration the underestimation due the reasons cited above.

In the present report, the current status of the prevalence and the distribution of leishmaniasis in the MENA were summarized based on the available and scattered reports. An overview of the Middle East and North Africa was summarized to well understand the aspects particular of the region. Leishmaniasis surveillance and control to prepare the countries of the region for future public health challenges were reviewed based on recent consortium innovation.

\section{Methodology}

The data presented in this review are gathered primarily from WHO reports for each country and from an extensive literature search on PubMed using the term "Leishmaniasis" followed by the name of each endemic country. Similar searches were carried out using the term "global distribution", "incidence", "prevention and control of leishmaniasis", "sandfly", "Leishmaniasis North Afrca". and "Leishmaniasis Middle East".

\section{Particularities of the middle East and North Africa region}

The Middle East and North Africa Union is comprised of approximately 20 countries including Morocco, Algeria, Tunisia, Libya, Egypt, Yemen, United Arabes Emirates, Syria, Saudi Arabia, Qatar, Palestinian territory, Oman, Lebanon, Kuwait, Jordan, Israel, Iraq, Iran, Djibouti, and Bahrain $^{13}$.

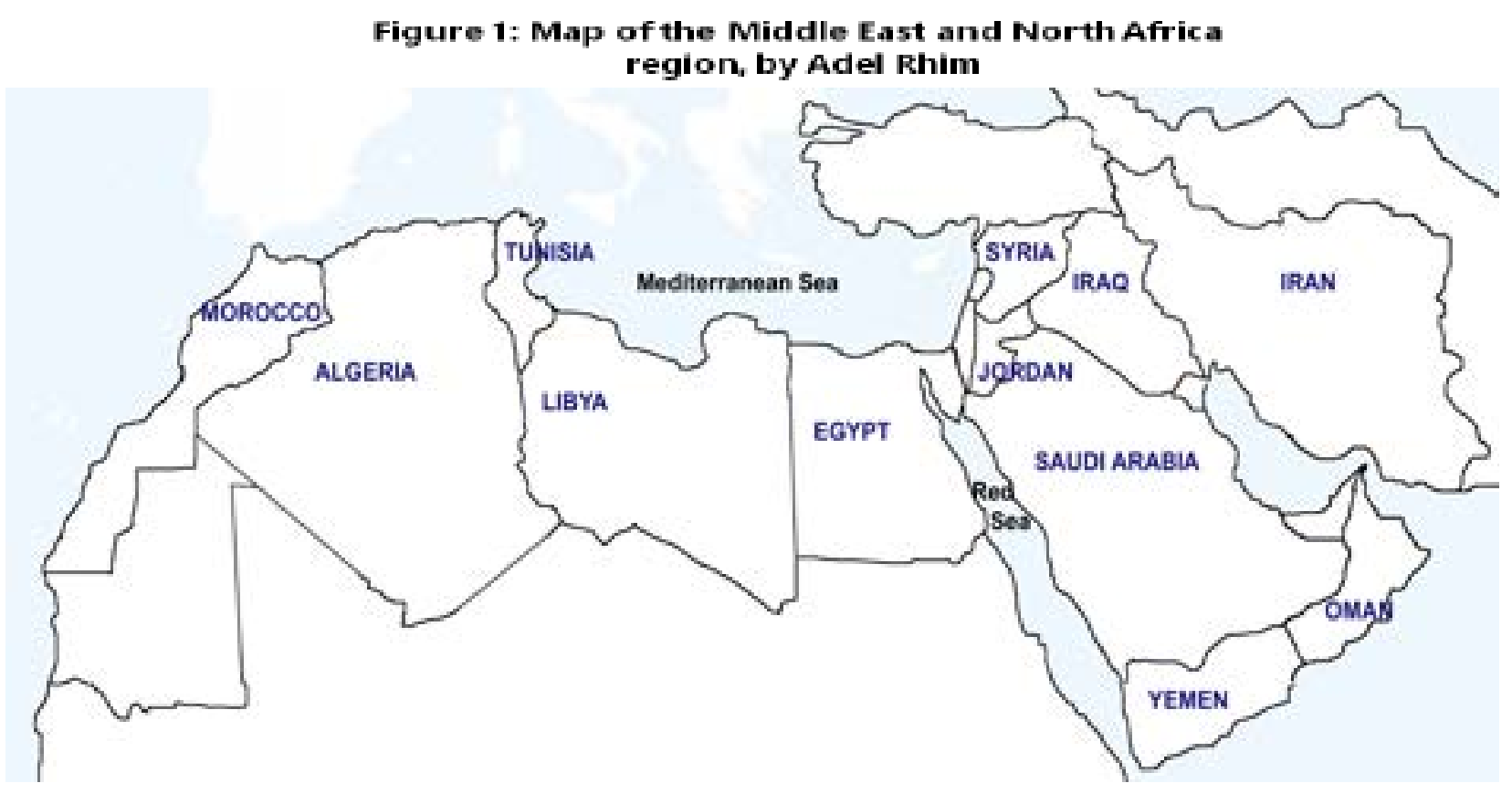


As shown Figure 1, our study was focused on the most important 12 countries, where the situation is serious and data are more or less available. The winds of unrest sweep through the MENA since 2011. It began in Tunisia and spread within weeks to Egypt, Yemen, Libya and Syria ${ }^{13}$. The MENA comprises a small share of the world's population (5\%), which is characterized by its youth. Egypt, Iran, Algeria, Morocco and Iraq are the most popular countries $^{14}$. It should be noted that the MENA showed the highest unemployment rate worldwide $(24 \%)$ associated with a slow down in economic growth (3\%). In this context, statistical studies carried out in 2005 confirmed that $3.6 \%$ of the MENA population is living on less than US $\$ 1.25$ per day, while $16.9 \%$ is living below US $\$ 2$ per day ${ }^{15}$ hence their vulnerability to the leishmaniasis and other neglected diseases. The highest percentages of people living in poverty are living in Yemen and Egypt compared to other MENA countries ${ }^{14}$ without forgetting Algeria, Djibouti, Iran, Iraq, Morocco, and Tunisia where living important percentage of impoverished people ${ }^{14,16}$. Globally, the World Bank classified most of MENA Countries as lower-middle-income countries ${ }^{17}$. Two other factors including modern conflicts ensuing in the geographic and political region and the lack of veterinary and public health were added to poverty factor and enhances the spread of leishmaniasis in the areas ${ }^{18}$.

\section{Cutaneous and visceral leishmaniasis}

It is important to remember that about two million cases of Leishmania are recorded yearly in 88 counrties $^{19}$. Authors suggested that this prevalence was underestimate and not precise due to misdiagnosis and inadequate reporting guidelines and the true numbers was at least five to eight times ${ }^{12,19}$ because of the non-declaration of the disease by more than the half of endemic countries. The incidence of the disease is still on the rise in countries with political instability including the $\mathrm{MENA}^{20}$ although it has reduced by half ${ }^{21}$ globally in the past decade.

However the different cycle of transmission and clinical expression, all Leishmania species are transmitted to humans via the bite of infected sand flies. Metacyclic promastigotes in the foregut or anterior midgut of the sandfly was regurgitated into the skin of the invertebrate during the blood meal of infected sandflies. Right after and rapidly, the promastigotes are taken up by phagocytic cells, including macrophages and neutrophils. The pro- mastigotes forms differentiate into a dividing, aflagellated amastigotes in the phagolysosome. It is important to note that an infected host is the origin of the parasite that exists in sandflies. After lysing host cells, the amastigotes transform into procyclic promastigotes. They use their flagella to attach to the fly midgut using surface glyconconjugates, a key step in establishment of the infection. About twenty five Phlebotomus ssp are involved in the transmission of $L$. major, L. tropica, L. infantum, and L. donovani, relevant species in the MENA areas among approximately 20 Leishmania spp. infect humans worldwide. Cutaneous and visceral forms of leishmaniasis are the most important protozoan infection in the MENA region ${ }^{22,23}$. Visceral leishmaniasis (VL) in the MENA is caused by L. donovani, L. infantum, and occasionally L. tropica. However, the causal agents of cutaneous leishmaniasis (CL) are L. major, $L$. tropica, and L. infantum, which lesion presentation slightly differs depending on the species. Different nonhumans reservoirs are involved in the transmission of ZL namely rodents, hyraxes, and canids. Globally, ZCL caused by L. major is transmitted mainly by $P$. papatasi and Psammomys and Meriones rodents. Anthroponotic cutaneous leishmaniasis (ACL) caused by L. tropica is transmitted by $P$. sergenti and gundi and byraxes although the cycle is mainly anthroponotic, as is the VL agent, $L$. donovani. Zoonotic visceral leishmaniasis (ZVL) caused by L. infantum is mainly zoonotic where candids are considered as the primary reservoir and man as an accidental host; however, anthroponotic cycles also have been characterized.

\section{Cutaneous leishmaniasis}

Two forms of cutanuous leishmaniasis exist in the MENA: anthroponotic and zoonotic caused by Leishmania (L.) tropica and L. major parasites, respectively.

\section{Zoonotic cutaneous leishmaniasis}

Foci of ZCL occur in all countries of the MENA with higher rates in Iran, Saudi Arabia, Morocco, Tunisia, Syria, Libya, and Iraq ${ }^{24-29}$. Iran and Saudi Arabia have the highest rate of ZCL. The disease is caused by L. major, which transmitted through mainly $P$. papatasi and its close relatives, $P$. duboscqi and P. salebi. Phlebotomus caucasicus has been mentioned as a vector in $\operatorname{Iran}^{30-34}$. It is important to note that $P$. papatasi is considered among the most widespread invasive sandflies species in the MENA and worldwide. The close association of these vectors with 
human habitation ensures transmission to humans from domestic and other animal reservoirs. Rodent species of Psammomys obesus, Meriones libycus, Meriones shawi, Nesokia indica, and Rhombomys opimus serving as non-human reservoirs $^{31}$. Psammomys obesus occur as reservoir of L. major in most foci between Morocco in the West and Syria and Saudi Arabia in the East. The great gerbil Rhombomys opimus maintains L. major in central and North-Western Iran. This parasite was transmitted through Meriones sha$w i$ in Southern Morocco and several Meriones species in South-Eastern and South-Western Iran where the bandicoot rat Nesokia indica was considered as a second reservoir. This disease affects mainly the arid areas of endemic countries which explain the important number of cases (600) in 2004 in US soldiers during the war against $\mathrm{Iraq}^{30}$. The breakdowns in public health system and the 8 years of war were the main causes of the emergence of the disease in its both forms in $\operatorname{Iraq}^{30}$.

\section{Anthroponotic cutaneous leishmaniasis}

Anthroponotic leishmaniasis caused by L. tropica and its closely related species Leishmania killicki $i^{35-37}$ and spread through $P$. sergenti and related species, circulates exclusively in humans mainly in urban areas. Several previous studies showed that $P$. sergenti is the proven or potential vector of $L$. tropica in many foci of ACL in the MENA ${ }^{38-}$ 39. This sandfly is known to have an endophilic behavior in rural and urban habitats in semi-arid bioclimates, which explain the transmission of parasites to humans from domestic and other animal reservoirs ${ }^{36,40-45}$. The parasite occurred in high number in Syria, Iran, Morocco, Yemen and Algeria ${ }^{31,33,34,46}$. Leishmania tropica is commonly stated to be anthroponotic. However, the relative paucity of CL cases in some countries of the MENA and their spatial distribution suggests that it might be a zoonosis. Infection occurs both in old housing and new suburban settlements and also in peripheral villages. In Tunisia, the North African gundi (Ctenodactylus gundi) was suspected to be the $L$. killicki reservoir since the end of the last century ${ }^{36,47}$ and recently was considered as a natural host of this parasite after identification of $L$. killicki from infected gundi ${ }^{49,50}$. However, it was the rock hyrax (Procavia capensis) in North Israel ${ }^{51,52}$. Indeed, previous studies showed that the rock hyrax is the proven reservoir of $L$. tropica. Its role as reservoir was confirmed by artificial infection and in natura ${ }^{51,53-55}$.

\section{Visceral leishmaniasis}

There are two different modes of transmission of visceral leishmaniasis in the MENA: Zoonotic visceral leishmaniasis (ZVL) is caused by L. infantum and Anthroponotic visceral leishmaniasis (AVL) caused by $L$. donovani.

\section{Zoonotic visceral leishmaniasis}

Zoonotic visceral leishmaniasis (ZVL) is caused by $L$. infantum, spread through several Phlebotomus spp. of the subgenus Larroussius and mainly $P$. perniciosusin more than one-half of the MENA countries, including Egypt, Iran, Iraq, Jordan, Lebanon, Libya, Morocco, Saudi Arabia, Syria, Tunisia, and Yemen $3^{0,31,56}$. According to the concerned countries and areas, P. perniciosus, P. longicupis, P. langeroni, $P$. perfiliewi, $P$. ariasi, $P$. galilaens, $P$. syriacus, $P$. tobbi, and $P$. halepensis acts as proven and potential vectors and the dog species of Canisfamiliaris acts as the main nonhuman reservoirs. However, other wild and domestic animals including Canidae and rodents were considered as secondary reservoirs after found them naturally infected ${ }^{57}$. Nevertheless, their own role as reservoirs in the transmission life cycle is not proven. Phlebotomus (P.) perniciosusis the most widespread vector of L.infantum (Protozoa, Trypanosomatidae) to humans and dogs in the MENA and is characterized by its endophilic behavior ${ }^{58-60}$. This disease is strongly related to low socio-economical levels and houses with deteriorated bad quality walls ${ }^{61}$.These conditions are suitable for L. infantum transmission ${ }^{59,62,63}$. Indeed, dogs have an important role in these agricultural areas including guarding houses and tending flocks. Furthermore, sandflies are strongly related to these biotopes by its different blood sources and by its suitable biotope for rest and egg-laying ${ }^{38,64}$. The number of cases of ZVL has risen in the MENA because global warming and land degradation, which together affect the epidemiology of leishmaniasis. As an example, hundreds of patients have been diagnosed yearly in NA countries since the 90's in comparison with just few cases registered before the 80's in the same countries ${ }^{59,65-67}$.

\section{Anthroponotic visceral leishmaniasis}

Anthroponotic visceral leishmaniasis (AVL) caused by $L$. donovani spreads through probably $P$. alexandri and P. orientalis occurs in Yemen and Saudi Arabia, where no accurate data are available ${ }^{31}$ without any nonhuman reservoir ${ }^{68-70}$. 
Strategic framework for leishmaniaisis in the MENA The main goal of the World Health Organization ${ }^{71}$ network for leishmaniasis surveillance and control is to reduce the prevalence of disease. To reach this goal, each country's health development activities should integrate these surveillance and control measures. Early diagnosis and treatment, control of sand fly populations, reservoir control, especially for zoonotic forms, health education and training, intersectoral collaboration, and partnership action are the global goals of this network ${ }^{31}$.

Here, the different goals of this network will be detailed as following: firstly, each country's health development activities should implement health education, community participation and risk assessment with special attention to program management, case detection and management, disease surveillance. Secondly, the detection of new emerging foci is of great importance to well conduct preventive measures, case diagnostic and management. The monitoring system should learn from already existing systems (strengths, weaknesses, failures and successes) and ameliorate them. Data should be collected correctly as maximum possible by professional staffs. Thirdly, each country's health development activities should create a regional network to share information and experiences, make medicines available to more patients who need them and extend the collaboration at the sub-regional scale. Fourthly and finally, each country's health development activities should encourage and develop cross-border cooperation, multisectoral and intersectoral collaboration to prepare the country for future and international public health challenges.

Since leishmaniasis has been a major public health problem in the MENA for many years, considerable scientific efforts and infrastructures have been allocated to control this severe yet neglected health problem. Recently, McDowell et al (2011) suggested an international research agenda for leishmaniasis in the $\mathrm{MENA}^{22}$. In fact, the collaboration between the USA and endemic countries of the MENA was improved in 2009 during a Leishmania research and policy conference held in Tunisia ${ }^{22}$. The possibility of the globalization of this disease by importation through immigrants, travelers, non-governmental organization workers, and even tourists raise the interest of the USA and other developed countries in Leishmania. In November 2016, scientists of member countries of the Institute Pasteur International Network including Morocco, Algeria, Tunisia, and Iran, which have similar characteristics and elements of CL diseases (parasites, vectors, and reservoir animals) meet in Tehran with scientists of Institute Pasteur in Paris and suggested a new consortium to develop an integrative research approach to better understand this disease $\mathrm{e}^{22,72}$. Leishmania genetics, host immune response, and vector transmission were the three main thematics, which need more investigations according to different participants. In this context, scientists insist that essential discoveries will be reported thanks to the dynamic interaction among these factors ${ }^{73}$. Indeed, the first thematic (Leishmania genetics) can engender novel vaccine candidates and drug-target against CL using Leishmania genetics and evolvability. The second thematic (host immune response) can engender the development of novel biomarkers for vaccine development and immunotherapy elucidating the host immune response to infections. The third thematic (vector transmission) can engender new insight into entomological risk assessment and vector control, and risk anticipation as a part of tasks dedicated to vector biology and transmission dynamics. However, health education and training at both the national and international levels will be of great importance of this consortium.

In summary, there are many challenges facing the successful control of cutaneous and visceral leishmaniasis. Leishmaniasis is still endemic in many poverty stricken and war torn areas, which complicate such efforts ${ }^{70}$. However, there is continuing research into the treatment of leishmaniasis and potentially vaccinations for the disease.

\section{Conflict of interest}

The author declare that there is no conflict of interest.

\section{References}

1. Reithinger R, Dujardin JC, Louzir H, Pirmez C, Alexander B, Brooker S. Cutaneous leishmaniasis. Lancet Infectious Diseases, 2007; 7(9): 581-596. DOI:10.1016/S14733099(07)70209-8

2. Pearson RD, Sousa AQ. Clinical spectrum of Leishmaniasis. Clinical Infectious Diseases, 1996; 22(1): 1-13. DOI: https://doi.org/10.1093/clinids/22.1.1

3. Abbas K, Musatafa MA, Abass S, Kheir MM, Mukhtar $\mathrm{M}$, et al. Mucosal leishmaniasis in a Sudanese patient. $A m$ J Trop Med Hyg. 2009; 80: 935-938. https://www.ncbi. 
nlm.nih.gov/pubmed/?term $=$ Abbas $+\mathrm{K} \% 2 \mathrm{C}+$ Musata$\mathrm{fa}+\mathrm{MA} \% 2 \mathrm{C}+$ Abass $+\mathrm{S} \% 2 \mathrm{C}+\mathrm{Kheir}+\mathrm{MM} \% 2 \mathrm{C}+$ Mukhta $\mathrm{r}+\mathrm{M} \% 2 \mathrm{C}+\mathrm{et}+\mathrm{al} .+(2009)+$ Mucosal

4. Elamin EM, Guizani I, Guerbouj S, Gramiccia M, El Hassan AM, et al. Identification of Leishmania donovani as a cause of cutaneous leishmaniasis in Sudan. Trans $R$ Soc Trop Med Hyg. 2008; 102: 54-57. DOI: 10.1016/j.trstmh.2007.10.005

5. Khalil EA, Musa AM, Elgawi SH, Meshasha A, Gamar Eldawla I, et al. Revival of a focus of visceral leishmaniasis in central Sudan. Ann Trop Med Parasitol. 2008; 102: 79-80. DOI: 10.1179/136485908X252269

6. Volf P, Benkova I, Myskova J, Sadlova J, Campino L, et al. Increased transmission potential of Leishmania major/ Leishmania infantum hybrids. Int J Parasitol. 2007; 37: 589_ 593. DOI: 10.1016/j.ijpara.2007.02.002

7. Ravel C, Cortes S, Pratlong F,Morio F, Dedet JP, et al. First report of genetic hybrids between two very divergent Leishmania species: Leishmania infantum and Leishmania major. Int J Parasitol. 2006; 36: 1383-1388. DOI: 10.1016/j.ijpara.2006.06.019

8. Sakthianandeswaren A, Foote SJ, Handman E. The role of host genetics in leishmaniasis. Trends Parasitol. 2009; 25: 383-391. DOI: 10.1016/j.pt.2009.05.004

9. Ben Hadj Ahmed S, Chelbi I, Kaabi B, Cherni S, Derbali $\mathrm{M}$, et al. Differences in the salivary effects of wild-caught versus colonized Phlebotomus papatasi (Diptera: Psychodidae) on the development of zoonotic cutaneous leishmaniasis in BALB/c mice. J Med Entomol. 2010; 47:74-79. https:// www.ncbi.nlm.nih.gov/pubmed/?term $=\mathrm{Ben}+\mathrm{Had}-$ $\mathrm{j}+\mathrm{Ahmed}+\mathrm{S} \% 2 \mathrm{C}+\mathrm{Chelbi}+\mathrm{I} \% 2 \mathrm{C}+\mathrm{Kaabi}+\mathrm{B} \% 2 \mathrm{C}+\mathrm{Ch}-$ erni $+\mathrm{S} \% 2 \mathrm{C}+$ Derbali $+\mathrm{M} \% 2 \mathrm{C}+$ et + al. $+2010 .+$ Differences

10. Laurenti MD, Silveira VM, Secundino NF, Corbett CE, Pimenta PP. Saliva of laboratory-reared Lutromyia longipalpis exacerbates Leishmania (Leishmania) amazonensis infection more potently than saliva of wildcaught Lutromyia longipalpis. Parasitol Int. 2009; 58: 220-226. DOI: 10.1016/j.parint.2009.05.005

11. Yin H, Norris DE, Lanzaro GC. Sibling species in the Llutzomyia longipalpis complex differ in levels of mRNA expression for the salivary peptide, maxadilan. Insect Mol Biol. 2000; 9: 309-314. https://www.ncbi.nlm.nih.gov/ pubmed $/$ ?term $=$ Yin $+\mathrm{H}^{\%} \% 2 \mathrm{C}+$ Norris $+\mathrm{DE} \% 2 \mathrm{C}+\mathrm{Lan}-$ zaro + GC+(2000) + Sibling + species + in + the + Llutzomyia+longipalpis + complex
12. World Health Organization. Control of the leishmaniases: report of a meeting of the WHO Expert Committee on the Control of Leishmaniases, Geneva, March 22-26 2010. WHO: Geneva; 2010. http://apps.who.int/ iris/handle/10665/44412

13. World Bank (2011a) Middle East and North Africa regional brief. Available: http://web.worldbank.org/WBSITE/EXTERNAL/COUNTRIES/

14. Population Reference Bureau (n.d.) Data Finder. Available: http://www.prb. org/DataFinder.aspx. Accessed 2011 June 15.

15. World Bank (n.d.) Poverty. Available: http://data. worldbank.org/topic/poverty. Accessed 26 June 2011b.

16. World Bank (n.d.) Poverty gap at $\$ 2$ a day (PPP) (\%). Available: http://data. worldbank.org/indicator/SI.POV. GAP2. Accessed 2011c June 26.

17. World Bank (n.d.) Data: Middle East \& North Africa. Available: http:// data.worldbank.org/region/MNA. Accessed 15 June 2011d.

18. Gwida M, Al Dahouk S, Melzer F, Rosler U, Neubauer $\mathrm{H}$, et al. Brucellosis- regionally emerging zoonotic disease? Croat Med J. 2010; 51: 289-295. https://www.ncbi. nlm.nih.gov/pubmed/?term $=\mathrm{G}$ wida $+\mathrm{M} \% 2 \mathrm{C}+\mathrm{Al}+\mathrm{Da}-$ houk $+\mathrm{S} \% 2 \mathrm{C}+$ Melzer $+\mathrm{F} \% 2 \mathrm{C}+$ Rosler $+\mathrm{U} \% 2 \mathrm{C}+\mathrm{Neu}-$ bauer $+\mathrm{H} \% 2 \mathrm{C}+\mathrm{et}+$ al. $+(2010)+$ Brucellosis-+regionally 19. World Health Organization. Leishmaniasis-diagnosis, detection and surveillance. Geneva: WHO; 2013. Available at: http://www.who.int/leishmaniasis/ surveillance/en/ (accessed November 30, 2013).

20. Gonzalez U. Cochrane reviews on neglected diseases: the case of cutaneous leishmaniasis. Cochrane Database Syst Rev. 2013; 3: ED000055. DOI: 10.1002/14651858. ED000055

21. Murray CJ, Vos T, Lozano R, Naghavi M, Flaxman AD, Michaud C, et al. Disability-adjusted life years (DALYs) for 291 diseases and injuries in 21 regions, 19902010: a systematic analysis for the Global Burden of Disease Study 2010. Lancet. 2012; 380:2197-223. PubMed. DOI: 10.1016/S0140-6736(12)61689-4

22. McDowell MA, Rafati S, Ramalho-Ortigao M, Ben Salah A. Leishmaniasis: Middle East and North Africa research and development priorities. PLoS Negl Trop Dis. 2011;5:e1219. DOI: 10.1371/journal.pntd.0001219

23. Leishmaniasis cases recorded among Syrian refugees in Iraqi Domise camp. July 16, 2013. Iraq: Alsumaria; 2013. Available at: http://www.alsumaria.tv/news/ 
79442/leishmaniasis-cases-recorded-among-syria/en (accessed June 2014).

24. Hamadto HA, Al FA, Farrag AB, Abdel Maksoud MK, Morsy TA. Zoonotic cutaneous leishmaniasis: reservoir host and insect vector in north Sinai, Egypt. J Egypt Soc Parasitol. 2007; 37: 843-50. https://www.ncbi. nlm.nih.gov/pubmed/?term=Hamadto $+\mathrm{HA} \% 2 \mathrm{C}+\mathrm{Al}+$ $\mathrm{FA} \% 2 \mathrm{C}+\mathrm{Farrag}+\mathrm{AB} \% 2 \mathrm{C}+\mathrm{Abdel}+\mathrm{Maksoud}+\mathrm{M}-$ $\mathrm{K} \% 2 \mathrm{C}+$ Morsy+TA.+Zoonotic+cutaneous

25. Emami MM, Yazdi M, Nilforoushzadeh M. Emergence of cutaneous leishmaniasis due to Leishmania major in a new focus of central Iran. Trans $\mathrm{R}$ Soc Trop Med Hyg. 2009; 103: 1257-62. PubMed. DOI: 10.1016/j.trstmh.2009.04.020

26. Mosleh IM, Geith E, Natsheh L, Abdul-Dayem M, Abotteen N. Cutaneous leishmaniasis in the Jordanian side of the Jordan Valley: severe under-reporting and consequences on public health management. Trop Med Int Health. 2008; 13: 855-60. DOI: 10.1111/j.13653156.2008.02063.x

27.El-Buni AA, JabealI, Ben-Darif AT.Cutaneous leishmaniasis in the Libyan Arab Jamahiriya: a study of the Yafran area. East Mediterr Health J. 2000; 6: 884-7. https:/ /www. ncbi.nlm.nih.gov/pubmed/?term=El-Buni+AA\%2C+Jabeal $+\mathrm{I} \% 2 \mathrm{C}+$ Ben-Darif + AT. + Cutaneous +leishmaniasis + in + the + Libyan + Arab

28. Rhajaoui M. Human leishmaniases in Morocco: a nosogeographical diversity [in French]. Pathol Biol (Paris). 2009 [Epub 2009 November 24]. DOI: 10.1016/j.patbio.2009.09.003

29. Chelbi I, Kaabi B, Béjaoui M, Derbali M, Zhioua E. Spatial correlation between Phlebotomus papatasi Scopoli (Diptera: Psychodidae) and incidence of zoonotic cutaneous leishmaniasis in Tunisia. J Med Entomol. 2009; 46: 400-2. PubMed. https://www.ncbi.nlm.nih.gov/pubmed/?term $=$ Chelbi $+\mathrm{I} \% 2 \mathrm{C}+\mathrm{Kaabi}+\mathrm{B} \% 2 \mathrm{C}+\mathrm{B} \% \mathrm{C} 3 \% \mathrm{~A}-$ $9 \mathrm{jaoui}+\mathrm{M} \% 2 \mathrm{C}+$ Derbali $+\mathrm{M} \% 2 \mathrm{C}+$ Zhioua + E. + Spatial + correlation + between + Phlebotomus

30. Weina PJ, Neafie RC, Wortmann G, Polheus M, Aronson NE Old world leishmaniasis: an emerging infection among deployed US military and civilian workers. Clin Infect. Dis 2004; 39: 1674-1680. DOI: 10.1086/425747 31. Postigo JA. Leishmaniasis in the World Health Organization Eastern Mediterranean Region. Int J Antimicrob Agents. 2010; 36 Suppl 1: S62-S65. DOI: 10.1016/j.ijantimicag.2010.06.023
32. Uthman MA, Satir AA, Tabbara KS. Clinical and histopathological features of zoonotic cutaneous leishmaniasis in Saudi Arabia. J Eur Acad Dermatol Venerol. 2005; 19: 431-436. DOI: 10.1111/j.1468-3083.2005.01210.x

33. AlSamarai AM, AlObaidi HS Cutaneous leishmaniasis in Iraq. J Infect Developing Countries. 2009; 3: 123-129. https://www.ncbi.nlm.nih.gov/pubmed/?term=AlSamarai+AM\%2C+AlObaidi+HS+(2009)+Cutaneous+leishmaniasis

34. Fathy FM, El-Kasah F, El-Ahwal AM. Emerging cutaneous leishmaniasis in Sirte-Libya: epidemiology, recognition and management. J Egypt Soc Parasitol. 2009; 39: 881-905. https://www.ncbi.nlm.nih.gov/pubmed/?ter$\mathrm{m}=\mathrm{Fathy}+\mathrm{FM} \% 2 \mathrm{C}+\mathrm{El}-\mathrm{Kas}$ ah $+\mathrm{F} \% 2 \mathrm{C}+\mathrm{E} 1-\mathrm{Ah}-$ wal $+\mathrm{AM}+(2009)+$ Emerging

35. Harrat Z, Boubidi SC, Pratlong F, Benikhlef R, Selt B, et al. Description of a dermatropic leishmania close to $L$. killicki (Rioux, Lanotte \& Pratlong 1986) in Algeria. Trans R Soc Trop Med Hyg. 2009; 103: 716-720. DOI: 10.1016/j. trstmh.2009.04.013

36. Tabbabi A, Ghrab J, Aoun K, Ready PD. \& Bouratbine, A. Habitats of the sandfly vectors of Leishmania tropica and $L$. major in a mixed focus of cutaneous leishmaniasis in SouthEast Tunisia. Acta Tropica, 2011a; 119:131-137. DOI: 10.1016/j.actatropica.2011.05.002

37. Tabbabi A, Bousslimi N, Rhim A, Aoun, K, Bouratbine A. First report on natural infection of Phlebotomus sergenti with Leishmania promastigotes in the cutaneous leishmaniasis focus in SouthEastern Tunisia. American Journal of Tropical Medicine and Hygiene, 2011b; 85: 646-647. DOI: 10.4269/ajtmh.2011.10-0681

38. Killick-Kendrick R. Phlebotomine vectors of the leishmaniasis: a review. Med. Vet. Entomol. 1990; 4, 1-24. https://www.ncbi.nlm.nih.gov/pubmed/2132963

39. Guilvard E, Rioux JA, Gallego, M., Pratlong, F., Mahjour, J., Martinez-Ortega, E., Dereure, J., Saddiki, A., Martini, A. Leishmania tropica in Morocco. III identification of 89 isolates from the vector Pblebotomus sergenti. Ann. Parasitol. Hum. Comp. 1991; 66: 96-99. DOI: 10.1051/parasite/199166396

40. Yahia H, Ready PD, Hamdani A, Testa, JM, Guessous, N. Regional differentiation of Phlebotomus sergenti in three Moroccan foci of cutaneous leishmaniasis cause by Leishmania tropica. Parasite. 2004; 11: 189-199. DOI: 10.1051/parasite/2004112189

41. Guernaoui S, Boumezzough A, Pesson B, Pichon G. 
Entomological investigations in Chichaoua: an emerging epidemic focus of cutaneous leishmaniasis in Morocco. J. Med. Entomol. 2005; 42: 697-701. https://www.ncbi.nlm. nih.gov/pubmed/16119562

42. Ramaoui K, Guernaoui S, Boumezzough A. Entomological and epidemiological study of a new focus of cutaneous leishmaniasis in Morocco. Parasitol. Res. 2008;103:859-863. DOI: 10.1007/s00436-008-1068-3

43. Boussaa S, Guernaoui S, Pesson B, Boumezzough A. Seasonal fluctuations of phlebotomine sand fly populations (Diptera: Psychodidae) in the urban area of Marrakech, Morocco. Acta Trop. 2005; 95: 86-91. DOI: 10.1016/j.actatropica.2005.05.002

44. Guernaoui S, Boumezzough A, Laamrani A. Altitudinal structuring of sand flies in the High-Atlas mountains (Morocco) and its relation to the risk of leishmaniasis transmission. Acta Trop. 2006; 97: 346-351. DOI: 10.1016/j.actatropica.2006.01.001

45. Guernaoui S, Boumezzough A. Habitat preferences of phlebotomine sandflies (Diptera: Psychodidae) in SouthWestern Morocco. J. Med. Entomol. 2009; 46:1187-1194. https://www.ncbi.nlm.nih.gov/pub$\mathrm{med} /$ ? term $=$ Guernaoui $\% 2 \mathrm{C}+\mathrm{S} . \% 2 \mathrm{C}+$ Boumezzough $\% 2 \mathrm{C}+\mathrm{A} . \% 2 \mathrm{C}+2009 .+$ Habitat + preferences + of + phlebotomine + sandflies

46. Mihoubi I, Picot S, Hafirassou N, de Monbrison F. Cutaneous leishmaniasis caused by Leishmania tropica in Algeria. Trans R Soc Trop Med Hyg. 2008; 102: 1157-1159. DOI: $10.1016 /$ j.trstmh.2008.06.013

47. Ben Ismail R, Ben Rachid MS. Epidémiologie des leishmanioses en Tunisie. In Maladies Tropicales Transmissibles. Edited by: Aupelf-Uref. John Libbey Enrobex, Paris; 1989:73-80.

48. Ashford RW. Cutaneous leishmaniasis: strategies of prevention. Clinics dermatol. 1999; 17:327-323. https://www.ncbi.nlm.nih.gov/pubmed/?term=Ashford + RW $\% 3 \mathrm{~A}+$ Cutaneous+leishmaniasis $\% 3 \mathrm{~A}+$ strategies + of + prevention. + Clinics + dermatol

49. Bousslimi N, , Ben-Abda I, Aoun K, Bouratbine A. Natural infection of North African gundi (Ctenodactylus gundi) by Leishmania Tropica in the focus of cutaneous leishmaniasis, SouthEast Tunisia. Am J Trop Med Hyg. 2012 Jun; 86 (6):962-5. DOI: 10.4269/ajtmh.2012.11-0572

50. Jaouadi K, Haouas N, Chaara D, Gorcii M, Chargui N, Augot D, Pratlong F, Dedet JP, Ettlijani S, Mezhoud H and Babba H. First detection of Leishmania killicki (Kinetoplastida, Trypanosomatidae) in Ctenodactylus gundi (Rodentia, (tenodactylidae), a possible reservoir of human cutaneous leishmaniasis in Tunisia. Parasites \& Vectors. 2011; 4:159. DOI: 10.1186/1756-3305-4-159

51. Talmi-Frank D, Jaffe CL, Nasereddin A, Warburg A, King $\mathrm{R}$, et al. Leishmania tropica in rock byraxes (Procavia capensis) in a focus of human cutaneous leishmaniasis. Am J Trop Med Hyg. 2010; 82: 814-818. DOI: 10.4269/ ajtmh.2010.09-0513

52. Vinitsky O, Ore L, Habiballa H, Cohen-Dar M. Geographic and epidemiologic analysis of the cutaneous leishmaniasis outbreak in Northern Israel, 2000-2003. IMAJ. 2010; 12: 652-656. https://www.ncbi.nlm.nih.gov/pub$\mathrm{med} /$ ?term $=$ Vinitsky $+\mathrm{O} \% 2 \mathrm{C}+\mathrm{Ore}+\mathrm{L} \% 2 \mathrm{C}+$ Habibal$\mathrm{la}+\mathrm{H} \% 2 \mathrm{C}+$ Cohen-Dar+M+(2010)+Geographic + and + epidemiologic

53. Svobodova' M, Volf P, Voty'pka J. Experimental transmission of Leishmania tropica to hyraxes (Procavia capensis) by the bite of Phlebotomus arabicus. Microbes Infect. 2006a; 8: 1691-1694. DOI: 10.1016/j.micinf.2006.01.024 54. Svobodova M, Votypka J, Peckova J, Dvorak V, Nasereddin A, Baneth G, Sztern J, Kravchenko V, Orr A, Meir D, Schnur LF, Volf P, Warburg A. Distinct transmission cycles of Leishmania tropica in 2 adjacent foci, northern Israel. Emerg Infect Dis. 2006b; 12: 1860-1868. DOI: 10.3201/eid1212.060497

55. Sang DK, Njeru WK, Ashford RW. A zoonotic focus of cutaneous leishmaniasis due to Leishmania tropica at Utut, Fift Valley Province, Kenya. Trans R Soc Trop MedHyg. 1994; 88: 35-37. https://www.ncbi.nlm.nih.gov/pub$\mathrm{med} /$ ?term $=\mathrm{Sang}+\mathrm{DK} \% 2 \mathrm{C}+\mathrm{Njeru}+\mathrm{WK} \% 2 \mathrm{C}+\mathrm{Ash}-$ ford + RW $\% 2 C+1994 .+A+$ zoonotic + focus + of + cutaneous+leishmaniasis

56. Al-Nahhas S, Shabaan M, Hammoud L, Al-Taweel A, Al-Jorf S. Visceral leishmaniasis in the Syrian Arab Republic: early detection using rK39. East Mediterr Health J. 2003; 9: 856-862. https://www.ncbi.nlm.nih.gov/pubmed/?ter$\mathrm{m}=\mathrm{Al}-\mathrm{Nahhas}+\mathrm{S} \% 2 \mathrm{C}+\mathrm{Shabaan}+\mathrm{M} \% 2 \mathrm{C}+$ Hammoud + $\mathrm{L} \% 2 \mathrm{C}+\mathrm{Al}-$ Taweel $+\mathrm{A} \% 2 \mathrm{C}+\mathrm{Al}$-Jorf $+\mathrm{S}+(2003)+$ Visceral+leishmaniasis

57. Ashford RW. Leishmaniasis reservoirs and their significance in control. Clin Dermatol. 1996; 14:523-32. https://www.ncbi.nlm.nih.gov/pubmed/?term=Ashford+RW.+Leishmaniasis + reservoirs + and + their+significance + in + control

58. Rioux J, Crozet H, Corre J-J, Simonneau P, Gras G. Les bases phyto-eÂcologiques de la lutte anticulicidienne. Cartographie des biotopes larvaires, ses applica- 
tions operationnelles dans le Midi mediterraneen. Annales

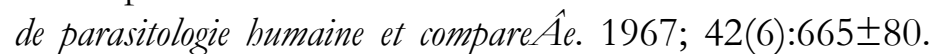
https://www.ncbi.nlm.nih.gov/pubmed/?term =Rioux + J $\% 2 \mathrm{C}+\mathrm{Crozet}+\mathrm{H} \% 2 \mathrm{C}+\mathrm{Corre}+\mathrm{J}-\mathrm{J} \% 2 \mathrm{C}+-$ Simonneau $+\mathrm{P} \% 2 \mathrm{C}+\mathrm{Gras}+\mathrm{G} .+$ Les + bases + phyto-e $\% \mathrm{C} 3 \% 82$ cologiques

59. Harrat Z, Pratlong F, Belazzoug S et al. Leishmania infantum and L. major in Algeria. Trans R Soc Trop Med. Hyg; 1996; 90: 625-9. https://www.ncbi.nlm.nih.gov/pubmed $/$ ?term $=$ Harrat $+\mathrm{Z} \% 2 \mathrm{C}+$ Pratlong $+\mathrm{F} \% 2 \mathrm{C}+$ Belazzoug $+\mathrm{S}+$ et + al. + Leishmania + infantum + and + L. + major+in+Algeria.

60. Izri MA, Belazzoug S, Boudjebla Y et al. Leishmania infantum MON-1 isolated from Phlebotomus perniciosus, in Kabylia (Algeria). Ann Parasitol Hum Comp. 1990; 65:151-2. https://www.ncbi.nlm.nih.gov/pubmed/?ter$\mathrm{m}=.+$ Izri $+\mathrm{MA} \% 2 \mathrm{C}+$ Belazzoug $+\mathrm{S} \% 2 \mathrm{C}+$ Boudjeb$\mathrm{la}+\mathrm{Y}+\mathrm{et}+\mathrm{al} .+\mathrm{Leishmania}+$ infantum $+\mathrm{MON}-1+$ isolat $\mathrm{ed}+$ from

61. Aoun K, Jeddi F, Amri F et al. Actualités épidémiologiques de la leishmaniose viscérale en Tunisie. Med Mal Infect. 2009; 39:775-9. DOI: 10.1016/j.medmal.2009.08.010 62. Evans TG, Teixeira MJ, McAuliffe IT et al. Epidemiology of visceral leishmaniasis in NorthEast Brazil. J Infect Dis. 1992; 166:1124-32. https://www.ncbi.nlm. nih.gov/pubmed/?term $=$ Evans + TG $\% 2 \mathrm{C}+$ Teixeira $+\mathrm{M}$ $\mathrm{J} \% 2 \mathrm{C}+\mathrm{McAuliffe}+\mathrm{IT}+\mathrm{et}+\mathrm{al} .+$ Epidemiology + of + visceral+leishmaniasis + in + northeast + Brazil

63. Killick-Kendrick, R. The biology and control of phlebotomine sand flies. Clinics in Dermatology. 1999; 17:27989. https://www.ncbi.nlm.nih.gov/pubmed/10384867 64. Ghrab J, Rhim A, Bach Hamba D et al. Phlebotominae (Diptera:Psychodidae) of human Leishmaniosis sites in Tunisia. Parasite. 2006; 13:23-33. DOI: 10.1051/parasite/2006131023

65. Aoun K, Amri F, Chouihi E et al. Epidémiologie de Leishmania (L.) infantum, L. major et L. killicki en Tunisie: Résultats et analyse de l'identification de 226 isolats humains et canins et revue de la littérature. Bull Soc Pathol Exo. 2008; 101:323-8. https://www.ncbi.nlm.nih.gov/ pubmed/18956815
66. Rioux JA. Trente ans de coopération Franco-marocaine sur les leishmanioses: Dépistage et analyse des foyers, facteurs de risque. Changements climatiques et dynamique noso-géographique. AAEIP; 2001, 168:90-101. http://www.scielo.br/scielo.php?script=sci_nlinks\&ref= 000099\&pid=S0102-31X200300040001700022\&lng=pt

67. Anderson C. Chronique du Kala-azar. Arch Inst Pasteur Tunis. 1938; 27:96-104.

68. Ready PD. Biology of phlebotomine sand flies as vectors of disease agents. Annu Rev Entomol. 2013; 58: 227-250. DOI: 10.1146/annurev-ento-120811-153557

69. Colacicco-Mayhugh MG, Grieco JP, Putnam JL, Burkett DA, Coleman RE. Impact of phlebotomine sand flies on United States military operations at Tallil Air Base, Iraq: 5. Impact of weather on sand fly activity. J Med Entomol. 2011; 48: 538-545. https://www.ncbi.nlm.nih.gov/pub$\mathrm{med} /$ ?term $=$ Colacicco-Mayhugh $+\mathrm{MG} \% 2 \mathrm{C}+$ Grieco + $\mathrm{JP} \% 2 \mathrm{C}+$ Putnam $+\mathrm{JL} \% 2 \mathrm{C}+$ Burkett $+\mathrm{DA} \% 2 \mathrm{C}+$ Coleman + RE $+(2011)+$ Impact + of + phlebotomine

70. Jacobson RL. Leishmaniasis in an era of conflict in the Middle East. Vector Borne Zoonotic Dis. 2011; 11: 247-258. DOI: $10.1089 / v b z .2010 .0068$

71. WHO. Report on the intercountry meeting on leishmaniasis control strategies in the Eastern Mediterranean Region; 27-30 October 2008; Aleppo, Syrian Arab Republic. Cairo: World Health Organization/EMRO; 2009. http://applications.emro.who.int/docs/intercountry_ meeting_ctd_053_14277.pdf

72. Rafati S, Kamhawi S, Valenzuela JG, et al. Building research and development capacity for neglected tropical diseases impacting leishmaniasis in the middle east and North Africa: a case study. Plos Negl Trop Dis. 2015; 9(8):e0003695. DOI: 10.1371/journal.pntd.0003695

73. Fariborz Bahrami, Gerald F. Späth \& Sima Rafati. Old World cutaneous leishmaniasis challenges in Morocco, Algeria, Tunisia and Iran (MATI): a collaborative attempt to combat the disease, Expert Review of Vaccines. 2017. DOI: 10.1080/14760584.2017.1311792. DOI: 10.1080/14760584.2017.1311792 